\title{
Identification of novel mitosis regulators through data mining with human centromere/kinetochore proteins as group queries
}

\author{
Aaron R Tipton ${ }^{1}$, Kexi Wang ${ }^{1}$, Peter Oladimeji ${ }^{1}$, Shermeen Sufi ${ }^{1}$, Zhidong Gu ${ }^{1,2}$ and Song-Tao Liu ${ }^{1 *}$
}

\begin{abstract}
Background: Proteins functioning in the same biological pathway tend to be transcriptionally co-regulated or form protein-protein interactions (PPI). Multiple spatially and temporally regulated events are coordinated during mitosis to achieve faithful chromosome segregation. The molecular players participating in mitosis regulation are still being unravelled experimentally or using in silico methods.

Results: An extensive literature review has led to a compilation of 196 human centromere/kinetochore proteins, all with experimental evidence supporting the subcellular localization. Sixty-four were designated as "core" centromere/kinetochore components based on peak expression and/or well-characterized functions during mitosis. By interrogating and integrating online resources, we have mined for genes/proteins that display transcriptional co-expression or PPI with the core centromere/kinetochore components. Top-ranked hubs in either co-expression or PPI network are not only enriched with known mitosis regulators, but also contain candidates whose mitotic functions are not yet established. Experimental validation found that KIAA1377 is a novel centrosomal protein that also associates with microtubules and midbody; while TRIP13 is a novel kinetochore protein and directly interacts with mitotic checkpoint silencing protein $\mathrm{p} 31^{\text {comet }}$
\end{abstract}

Conclusions: Transcriptional co-expression and PPI network analyses with known human centromere/kinetochore proteins as a query group help identify novel potential mitosis regulators.

Keywords: Centromere, Kinetochore, Centrosome, Data mining, Protein-protein interaction, Co-expression

\section{Background}

Mitosis is a complicated cellular process involving extensive structural reorganizations in many subcellular compartments and a sequence of highly orchestrated events. The temporal and spatial changes in mitotic cells are tightly regulated to ensure high fidelity of genomic transmission during cell division. Mitosis is initiated by accumulation of active kinase complexes formed between mitotic cyclins (cyclin $\mathrm{A}$ and $\mathrm{B}$ in human) and master mitosis regulator CDC2 (or CDK1) at the G2/M transition [1]. The expression of many other mitosis regulators also peaks during G2/M phase, some of which share the common control by transcription factors such

\footnotetext{
*Correspondence: sliu@utnet.utoledo.edu

'Department of Biological Sciences, University of Toledo, Toledo, OH 43606, USA

Full list of author information is available at the end of the article
}

as Fox M1 and the DREAM complex [2,3]. Chromosome condensation appears during prophase, concurring with reorganization of microtubule cytoskeleton into mitotic spindles and separation of duplicated centrosomes to opposite sides of the nucleus. The activity of cyclin A/ CDC2 lasts until nuclear envelope breakdown when cyclin $\mathrm{A}$ is degraded [4]. The cyclin $\mathrm{B} / \mathrm{CDC} 2$ complex, together with many other chromosome and microtubule associated proteins, promotes the formation of bipolar spindle and chromosome congression to the metaphase plate [1]. Cyclin B is then destructed after ubiquitylation by the anaphase promoting complex/cyclosome (APC/ C) $[1,5]$. Loss of cyclin $\mathrm{B} / \mathrm{CDC} 2$ activity ensures unidirectional progression of mitosis [6]. Sister chromatids separate and move to the opposite spindle poles after anaphase onset. Chromosomes then decondense, and the nuclear envelope reforms during telophase. When cytokinesis is completed, the abscission occurs at the 
midbody between two daughter cells, the spindle is disassembled and cells flatten out into interphase morphology again.

The centromeres are specialized loci on chromosomes that form primary constrictions during mitosis. There are currently 18 known human proteins constitutively associating with centromeres throughout the cell cycle [7]. The kinetochores are macromolecular protein complexes built upon centromeres to connect with spindle microtubules [8]. Kinetochores are dynamic structures that are assembled and disassembled at each sister chromatid during each and every mitosis [8]. Kinetochores also harbour activities contributing to chromosome movement throughout mitosis and the spindle assembly checkpoint (SAC) [5]. The SAC monitors kinetochoremicrotubule attachment status to inhibit activation of the APC/C until the metaphase-to-anaphase transition. Under electron microscope centromeres and kinetochores are contiguous structurally, and both play important roles in regulating chromosome segregation. We will use the term "the centromere/kinetochore complex" in this paper to reflect the intertwined relationship between the two subcellular structures.

Although the knowledge of proteins localized at the centromere/kinetochore complex has increased exponentially in the past few years [7-11], we still have much to learn about the proteins that contribute to the spatial and temporal regulation of mitosis. As indicated in recent reports, without a "parts list" of critical molecular players, it is impossible to reach a comprehensive understanding about mitosis and its connections with tumorigenesis and cancer drug effects [9,10,12]. Recent genomics and proteomics research has revealed that proteins in the same functional modules are usually transcriptionally co-expressed and/or organized into clusters in PPI networks (e.g. [13-15]). Many publicly available bioinformatics resources have deposited data obtained from large scale co-expression profiling and PPI studies, and provided tools to retrieve and organize the data.

As an end user interested in taking advantage of the huge amount of genomics and proteomics data in the public databases, we first conducted exhaustive literature review and compiled a list of 196 human centromere/ kinetochore proteins, and selected 64 among them as "core" components with well-characterized mitotic functions. By interrogating and integrating available online resources using the 64 core proteins as a query group, we have then identified potential novel mitosis regulators among top-ranking genes/proteins that co-express or interact with the 64 core centromere/kinetochore components. Experimental validation has identified one novel kinetochore protein TRIP13 and two novel centrosomal proteins KIAA1377 and DDX39.

\section{Results and discussion}

\section{Compiling a comprehensive list of human centromere/} kinetochore proteins

Several reviews have previously summarized known centromere/kinetochore proteins in human cells [7$11,16,17]$. Due to rapid progress in the field and extensive use of aliases in literature, omissions in the published lists have become obvious; therefore we carried out an exhaustive literature search aiming to compile a comprehensive list of human centromere/kinetochore proteins. A protein is defined as centromere/ kinetochore-localized only when experimental evidence such as immunofluorescence or fluorescent protein fusions supported the claims (except several condensin and cohesin subunits, see below). As updated until April 30, 2012, a total of 196 human proteins correlating to specific genes have been localized at the centromere/kinetochore complex in published literature (Additional file 1: Table S1 and references therein). In addition, a phospho-specific epitope, recognized by monoclonal antibody 3 F3/2 [18], resides in kinetochore proteins. The epitope, generated at least partially by Plk1 kinase, is likely to be found at multiple centromere/kinetochore proteins $[19,20]$. Some proteins carrying 3 F3/2 epitopes have been determined (e.g. BUBR1) [21], but many remain to be characterized. Among all the centromere/kinetochore proteins, only two cohesin subunits encoded by Rec8 and STAG3 are meiosis specific. Not all condensin and cohesin subunits have been experimentally localized at the centromere/kinetochore complex, but both condensin and cohesin complexes are essential non-histone structural components along chromosomes, and play important roles in chromosome dynamics throughout the cell cycle, we therefore tentatively include all condensin and cohesin subunits as centromere/kinetochore proteins [22,23]. To facilitate future research on the centromere/kinetochore proteins, in Table S1 we included gene symbols, Entrez gene IDs and common aliases for each gene.

When compared to previous summaries, the compilation has significantly expanded the list of known human centromere/kinetochore proteins, from $\sim 120$ to 196. The list still did not include all the subunits of several well-characterized protein complexes such as the dynein-dynactin complex and the $\gamma$-tubulin ring complex, both shown to associate with the centromere/ kinetochore [24]. Most likely the missing subunits are also targeted to the centromere/kinetochore as part of the protein complexes but as yet the localization has not been experimentally demonstrated. We will also report TRIP13 as a novel kinetochore protein below. A recent mass spectrometry based study estimated a total of $\sim 200$ kinetochore proteins [12]. Our survey indicates that the human centromere/kinetochore is indeed a complicated structure with constitutive and transient components easily exceeding 200 proteins. 
Table 1 The 64 core centromere-kinetochore components as queries for database searches

\begin{tabular}{|c|c|c|c|c|c|c|c|}
\hline \multirow{2}{*}{$\begin{array}{l}\text { Gene } \\
\text { Symbol }\end{array}$} & \multirow{2}{*}{$\begin{array}{l}\text { Number of } \\
\text { datasets in } \\
\text { Gene Sorter }\end{array}$} & \multirow{2}{*}{$\begin{array}{l}\text { Occurrences in combined } \\
\text { Gene Sorter "top 50" } \\
\text { co-expression list }\end{array}$} & \multirow[t]{2}{*}{ Notes } & $\overline{\text { MIS12 }}$ & 2 & & \\
\hline & & & & MLF1IP & 2 & 20 & CENPU \\
\hline APITD1 & 3 & 2 & CENPS & NDC80 & 3 & 12 & \\
\hline AURKB & 3 & & & NEK2 & 3 & 13 & \\
\hline BIRC5 & 3 & 1 & & NSL1 & 2 & 1 & \\
\hline BUB1 & 3 & 20 & & NUF2 & 2 & 7 & \\
\hline BUB1B & 3 & 30 & & OIP5 & 3 & 20 & MIS18B \\
\hline BUB3 & 3 & & & PLK1 & 3 & 19 & \\
\hline C14orf106 & 2 & & Mis18BP1 & PMF1 & 3 & & \\
\hline C21orf45 & 2 & 1 & Mis18A & $\mathrm{RCC2}$ & 2 & & TD60 \\
\hline C6orf173 & 1 & 4 & CENPW & SGOL1 & 1 & 2 & \\
\hline CASC5 & 2 & 3 & KNL1 & $\mathrm{SGOL} 2$ & 1 & 5 & \\
\hline CCDC99 & 2 & 3 & Spindly & SKA1 & 2 & 4 & C18orf24 \\
\hline CDC20 & 3 & 7 & & SKA & 2 & 2 & FAM33A \\
\hline CDCA8 & 2 & 19 & Borealin & SKA3 & 2 & 9 & C13orf3 \\
\hline CENPA & 3 & 14 & & SPC24 & 2 & 2 & \\
\hline CENPB & 3 & & & SPC25 & 3 & 15 & \\
\hline CENPC1 & 3 & & & STRA13 & 3 & & CENPX \\
\hline CENPE & 3 & 19 & & TTK & 3 & 15 & \\
\hline CENPF & 3 & 11 & & ZW10 & 2 & 6 & \\
\hline CENPH & 2 & 2 & & ZWILCH & 2 & 6 & \\
\hline CENPI & 3 & & & ZWINT & 3 & 34 & \\
\hline CENPK & 2 & 3 & & Sum & 155 & 422 & \\
\hline CENPL & 2 & & & Average & & 6.59 & \\
\hline
\end{tabular}

CENPN 2

CENPO 2

CENPP 2

$\begin{array}{lll}\text { CENPQ } 2 & 2\end{array}$

CENPT 2

CENPV 2

Table 1 The 64 core centromere-kinetochore components as queries for database searches (Continued)

We compared our list of human centromere/kinetochore proteins to annotations in Gene Ontology (GO) (http:// www.geneontology.org/) [25]. The GO term search returned 49 categories containing "centromere" and 31 containing "kinetochore" in the GO titles or definitions. Not all these GO categories contain human proteins. A total of 247 human proteins have been annotated in GO to be involved in centromere- or kinetochore-related localization, functions or processes, of which 128 appeared in our list of centromere/kinetochore proteins (Additional file 2: Table S2). Among the remaining 119 $\mathrm{GO}$ annotated centromere/kinetochore proteins, some may participate in regulation of centromere/kinetochore functions but do not localize at the structure themselves (e.g. proteins encoded by SUGT1 and SENP6) [26,27]. Some others such as CENPBD1 were annotated by inference without experimental evidence. A few more genes (e.g. $B A Z 1 B$ ) have been localized in other species but not in human cells. Proteins listed in the later two categories are worthy of further exploration in order to completely catalogue human centromere/kinetochore components 
Table 2 Top-ranking genes that co-express with 64 core centromere-kinetochore components

\begin{tabular}{|c|c|}
\hline Genes & $\begin{array}{l}\text { Occurrences in combined } \\
\text { Gene Sorter "top 50" } \\
\text { co-expression list }\end{array}$ \\
\hline ZWINT & 34 \\
\hline TRIP13 & 31 \\
\hline BUB1B & 30 \\
\hline CCNB2 & 30 \\
\hline CHEK1 & 27 \\
\hline KIF14 & 26 \\
\hline STIL & 26 \\
\hline PTTG1 & 25 \\
\hline RRM1 & 25 \\
\hline ESPL1 & 24 \\
\hline $\mathrm{NCAPH}$ & 24 \\
\hline ITGB3BP & 23 \\
\hline $\mathrm{KIF} 2 \mathrm{C}$ & 23 \\
\hline RACGAP1 & 22 \\
\hline RFC4 & 22 \\
\hline FOXM1 & 21 \\
\hline BUB1 & 20 \\
\hline CCNB1 & 20 \\
\hline CKS1B & 20 \\
\hline DBF4 & 20 \\
\hline FANCI & 20 \\
\hline MLF1IP & 20 \\
\hline NUSAP1 & 20 \\
\hline OIP5 & 20 \\
\hline TPX2 & 20 \\
\hline $\mathrm{CDC2}$ & 19 \\
\hline CDCA8 & 19 \\
\hline CENPE & 19 \\
\hline HMMR & 19 \\
\hline MELK & 19 \\
\hline PLK1 & 19 \\
\hline SMC4 & 19 \\
\hline TMPO & 18 \\
\hline UBE2C & 18 \\
\hline CDC45L & 17 \\
\hline CDCA3 & 17 \\
\hline RFC3 & 17 \\
\hline ASF1B & 16 \\
\hline CDKN3 & 16 \\
\hline KIF11 & 16 \\
\hline MCM2 & 16 \\
\hline PPIL5 & 16 \\
\hline
\end{tabular}

Table 2 Top-ranking genes that co-express with 64 core centromere-kinetochore components (Continued)

\begin{tabular}{|c|c|}
\hline RFC5 & 16 \\
\hline SPAG5 & 16 \\
\hline CDC25A & 15 \\
\hline CDC6 & 15 \\
\hline CDCA5 & 15 \\
\hline PCNA & 15 \\
\hline SPC25 & 15 \\
\hline TTK & 15 \\
\hline CDK2 & 14 \\
\hline CENPA & 14 \\
\hline GMPS & 14 \\
\hline KIFC1 & 14 \\
\hline KPNA2 & 14 \\
\hline PBK & 14 \\
\hline SMC2 & 14 \\
\hline TIMELESS & 14 \\
\hline TYMS & 14 \\
\hline CKAP2 & 13 \\
\hline DDX39 & 13 \\
\hline DTL & 13 \\
\hline GMNN & 13 \\
\hline MRPL39 & 13 \\
\hline NEK2 & 13 \\
\hline PSMG1 & 13 \\
\hline TTF2 & 13 \\
\hline WHSC1 & 13 \\
\hline ABCF1 & 12 \\
\hline IGF2BP3 & 12 \\
\hline MCM4 & 12 \\
\hline NDC80 & 12 \\
\hline POLE2 & 12 \\
\hline RNASEH2A & 12 \\
\hline SUPT16H & 12 \\
\hline UBE2T & 12 \\
\hline AK129567 & 11 \\
\hline CENPF & 11 \\
\hline CTPS & 11 \\
\hline DLGAP5 & 11 \\
\hline DUT & 11 \\
\hline KNTC1 & 11 \\
\hline MAD2L1 & 11 \\
\hline NUP155 & 11 \\
\hline PAK6 & 11 \\
\hline CCNA2 & 10 \\
\hline
\end{tabular}


Table 2 Top-ranking genes that co-express with 64 core centromere-kinetochore components (Continued)

\begin{tabular}{|c|c|}
\hline$\overline{C D C A 7}$ & 10 \\
\hline KIF2OB & 10 \\
\hline MCM3 & 10 \\
\hline WDR12 & 10 \\
\hline ARHGAP11A & 9 \\
\hline AURKA & 9 \\
\hline BLM & 9 \\
\hline C13orf3 & 9 \\
\hline CHTF18 & 9 \\
\hline $\mathrm{EZH} 2$ & 9 \\
\hline GINS1 & 9 \\
\hline HJURP & 9 \\
\hline $\mathrm{MICB}$ & 9 \\
\hline NCAPD2 & 9 \\
\hline NUP107 & 9 \\
\hline NUP205 & 9 \\
\hline PAXIP1 & 9 \\
\hline PKMYT1 & 9 \\
\hline PPAT & 9 \\
\hline TOP2A & 9 \\
\hline TROAP & 9 \\
\hline TSR1 & 9 \\
\hline TUBGCP4 & 9 \\
\hline Sum & 1674 \\
\hline Average & 15.36 \\
\hline
\end{tabular}

(Additional file 2: Table S2). However, SS18L1 may be mistakenly annotated because the acronym of one of its alias, CREST, is identical to the commonly used autoimmune antibody to stain centromeres.

\section{Genes co-expressing with 64 core centromere/ kinetochore components}

Transcriptional co-expression profiling has been extensively used to uncover functional gene modules involved in common biological processes [15,28-33]. These modules can be detected through comparing the similarity of gene expression patterns using Pearson correlation coefficient or other metrics. Value-based and rank-based methods have been developed to construct the co-expression network. Advantages of the rank-based method have been discussed in recent publications [34,35].

In our initial efforts, we adopted a simple rank-based method to retrieve genes that co-express with a selection of 64 "core" centromere/kinetochore components (Table 1, also marked by asterisks in Additional file 1: Table S1). The 64 genes were chosen based on higher expression and/or better characterized functions in mitosis. The selection, when used collectively as a query group, is expected to reduce noises common in any association studies and enhance the specificity in retrieving mitosis-relevant genes. Upon querying the Human Gene Sorter with the 64 genes, we extracted and ranked a total of 3828 genes that appeared at least once in a combined list of "top 50" co-expressing genes (Additional file 3: Table S3, see Methods for details). Forty-six of the 64 queries were represented in the combined list, with a total of 422 occurrences (Table 1). Moreover, 111 of 196 known centromere/kinetochore proteins appeared 680 times in total. The representation of both groups was significantly higher than by chance ( $\mathrm{Z}$ scores at 13.52 and 7.66 respectively, $\mathrm{P}<0.001$ ).

The genes that appeared more than 9 times in the combined co-expression list were summarized in Table 2. ZWINT, a well-characterized kinetochore protein, was represented 34 times in the combined list and ranked at the top [36]. Surprisingly, the second-ranking gene TRIP13 has never previously been associated with mitosis regulation but will be further characterized in this work as a novel kinetochore component (see below). GO term enrichment analyses of the genes in Table 2 indicated significantly higher representation of genes functioning in mitosis (Additional file 4: Table S4). A few categories of genes participating in DNA replication were also enriched in the results. Despite the possibility that the co-expression search may have recovered genes generally important for cell proliferation, it should be noted that at least some of the genes (e.g. RFC complex subunits-encoding CHTF18, RFC3, RFC4, RFC5) are critical for cohesion establishment during $\mathrm{S}$ phase $[22,37]$. As a further validation of the search strategy, we noticed certain genes in Table 2 have only been experimentally confirmed to participate in mitosis regulation in recent years, including those encoding centrosomal proteins STIL [38] and HMMR (RHAMM, [39]); centromere proteins RACGAP1 ([40]) and SUPT16H (Spt16 subunit of FACT complex, [41]); and other recently identified mitotic proteins NUSAP (involved in spindle organization, [42]) and CKAP2 (spindle function, [43]). This group can also be extended to include ITGB3BP (encoding CENP-R), MLF1IP (encoding CENP-U), OIP5 (Mis18ß), and HJURP, which all encode newly identified centromere proteins $[44,45]$. Although the later group of genes were among the 64 queries, they were so highly represented that they would still be retrieved if most of the constitutive centromere proteins (CENP-I to CENP$\mathrm{X}$ ) were omitted from queries. In addition, Table 2 and Additional file 3: Table S3 also contain several subunits of origin recognition complexes (ORC1L, ORC2L, ORC4L, ORC5L, ORC6L), $\gamma$-tubulin ring complexes (TUBGCP2, TUBGCP4, TUBGCP5), and condensin and 
Table 3 Top-ranking non-query genes whose encoded proteins interact with 64 core centromere-kinetochore components

\begin{tabular}{|c|c|c|c|c|}
\hline Ranking & Gene ID & $\begin{array}{l}\text { Gene Official } \\
\text { Symbol }\end{array}$ & $\begin{array}{l}\text { Total } \\
\text { interactions }\end{array}$ & $\begin{array}{l}\text { Interactions with } \\
64 \text { queries }\end{array}$ \\
\hline 22 & 10038 & PARP2 & 6 & 3 \\
\hline 36 & 10717 & $A P 4 B 1$ & 4 & 2 \\
\hline 37 & 8881 & $C D C 16$ & 12 & 3 \\
\hline 43 & 996 & $C D C 27$ & 26 & 4 \\
\hline 47 & 51434 & ANAPC7 & 9 & 2 \\
\hline 48 & 26271 & FBXO5 & 6 & 2 \\
\hline 49 & 8546 & $A P 3 B 1$ & 12 & 2 \\
\hline 50 & 5528 & PPP2R5D & 11 & 2 \\
\hline 51 & 23468 & $C B \times 5$ & 35 & 4 \\
\hline 53 & 5494 & PPM1A & 16 & 2 \\
\hline 54 & 9400 & RECQL5 & 16 & 2 \\
\hline 56 & 5525 & PPP2R5A & 21 & 2 \\
\hline 57 & 10982 & MAPRE2 & 8 & 2 \\
\hline 58 & 675 & $B R C A 2$ & 28 & 2 \\
\hline 59 & 891 & CCNB1 & 35 & 2 \\
\hline 60 & 51421 & AMOTL2 & 11 & 2 \\
\hline 61 & 57562 & KIAA1377 & 81 & 4 \\
\hline 62 & 163 & $A P 2 B 1$ & 33 & 2 \\
\hline 63 & 22981 & NINL & 37 & 2 \\
\hline 64 & 11335 & $C B \times 3$ & 18 & 2 \\
\hline 65 & 7277 & TUBA4A & 61 & 3 \\
\hline 66 & 10459 & MAD2L2 & 13 & 2 \\
\hline 67 & 5684 & PSMA3 & 37 & 2 \\
\hline 68 & 890 & CCNA2 & 36 & 2 \\
\hline 69 & 324 & $A P C$ & 43 & 3 \\
\hline 70 & 162 & $A P 1 B 1$ & 21 & 2 \\
\hline 71 & 22919 & MAPRE 1 & 16 & 2 \\
\hline 72 & 1874 & $E 2 F 4$ & 78 & 3 \\
\hline 73 & 26258 & PLDN & 21 & 2 \\
\hline 74 & 3066 & HDAC2 & 85 & 3 \\
\hline 75 & 142 & PARP1 & 56 & 3 \\
\hline 76 & 983 & $C D C 2$ & 131 & 4 \\
\hline 77 & 5515 & PPP2CA & 59 & 2 \\
\hline 78 & 7343 & UBTF & 27 & 2 \\
\hline 79 & 81565 & NDEL 1 & 26 & 2 \\
\hline 80 & 55290 & BRF2 & 57 & 2 \\
\hline 81 & 3065 & $\mathrm{HDACl}$ & 162 & 5 \\
\hline 82 & 5499 & PPPICA & 82 & 3 \\
\hline 83 & 1639 & DCTN1 & 47 & 2 \\
\hline 84 & 203068 & TUBB & 95 & 2 \\
\hline 85 & 23043 & TNIK & 90 & 2 \\
\hline 86 & 28964 & GIT1 & 53 & 2 \\
\hline
\end{tabular}

Table 3 Top-ranking non-query genes whose encoded proteins interact with $\mathbf{6 4}$ core centromere-kinetochore components (Continued)

\begin{tabular}{lllll}
\hline 87 & 1869 & E2F1 & 89 & 3 \\
88 & 3692 & EIF6 & 101 & 2 \\
89 & 5921 & RASA1 & 69 & 2 \\
90 & 55183 & RIF1 & 106 & 2 \\
91 & 5764 & PTN & 86 & 2 \\
92 & 8848 & TSC22D1 & 103 & 2 \\
93 & 11156 & PTP4A3 & 101 & 2 \\
94 & 7046 & TGFBR1 & 160 & 2 \\
95 & 5925 & RB1 & 156 & 2 \\
96 & 7428 & VHL & 208 & 2 \\
97 & 7157 & TP53 & 315 & 2 \\
98 & 7189 & TRAF6 & 369 & 2 \\
99 & 7532 & YWHAG & 309 & 2 \\
\hline
\end{tabular}

cohesin complexes, supporting the roles of these complexes at kinetochores or in mitosis $[24,46,47]$.

The genes co-expressing with 64 centromere/kinetochore components were further analysed using the CoExSearch program which accepts a group of queries to search and rank common co-expressing genes [48,49] (see Methods for details). As seen in Additional file 5: Table S5, 37 out of the 64 genes are found among the top 300 genes (no gene chip data for CENP-P in CoExSearch). In addition, the CoExSearch and Gene Sorter "top 300" lists share 123 genes, with TRIP13 among them (Additional file 6: Table S6). Due to coordination of many events in orchestrating mitosis progression, it should not be surprising that many among the 123 genes encode proteins that participate in different aspects of mitosis regulation, even though the query is a group of centromere/kinetochore proteins. Again, some among the 123 genes have only recently been associated with mitotic functions or structures such as FANCD2, FANCI and HYLS1[50,51]. Future efforts will be directed to analyze those that still do not have defined mitotic functions (marked by "?" in Additional file 6: Table S6).

\section{Proteins interacting with 64 core centromere/kinetochore components}

We then used POINeT website to obtain the "sub-network specific" PPI data with the 64 core centromere/kinetochore proteins collectively as a query group (see Methods for details) $[52,53]$. The tool was chosen mainly because it distinguishes a protein's total interactors from the interactors within a "sub-network" (in this case determined by the group of 64 query genes). The tool partially solved the problem of retrieving too many "false positive" interactors that may share no functions with the queries. Fifty-eight 
out of 64 queries returned interactors, with 452 nonredundant PPIs involving 352 interactors (including queries) retrieved. Top ranked non-query proteins that tend to interact with the core centromere/kinetochore proteins is presented in Table 3 and a full list in Additional file 7: Table S7. The functional relevance of the ranking was supported by several lines of evidence. First, the first 21 and a total of 44 in the list encode query proteins, indicating the clustering of search results. Second, some non-query proteins such as different isoforms of regulatory $B$ subunit of phosphatase 2A (two encoded by PPP2R5A and PPP2R5D in the list) were recently shown to localize at kinetochores and affect kinetochore-microtubule interactions [54,55]. In addition, many among the top-ranked non-query genes encode known centromere/kinetochore or mitotic regulatory proteins such as PARP2, CBX5 (encoding $\mathrm{HP} 1 \alpha$ ), CCNB1 (encoding cyclin $\mathrm{B} 1$ ); microtubule subunits and associated proteins TUBA4A and MAPRE2 (encoding EB2); proteins involved in mitotic ubiquitylation and regulation: $C D C 16$, $A N A P C 7, C D C 27$ (three APC/C subunits), FBXO5 (encoding Emi1, an APC/C inhibitor), MAD2L2 (another APC/C inhibitor) and PSMA3 (a proteasome subunit).

The mitotic functions of several other proteins are less well characterized but they were all reported in literature to interact with at least one of the 64 centromere/kinetochore proteins. Of interest, adapter proteins AP4B1, AP3B1 and AP2B1 interact with mitotic checkpoint kinases BUBR1 and BUB1, but the mitotic functions of the association have not been addressed [56]. However, clathrin has recently been shown to affect the spindle integrity during mitosis (for example, [57,58]), raising the possibility that these vesicle-trafficking proteins may indeed have mitotic functions. In addition, RECQL5 and BRCA2, two proteins involved in DNA repair, are of interest. BRCA2 has been localized at centrosomes and may affect genomic stability by altering centrosome behaviour [59]. Furthermore, KIAA1377 not only is localized at the midbody [52], but also interacts with kinetochore proteins ATRX, BMI1, CCDC99 (Spindly), MAD2L1BP (p31 $\left.{ }^{\text {comet }}\right)$, PMF1 and other known mitosis regulators (http://www.ncbi.nlm. nih.gov/gene?term=kiaa1377). Interestingly, TRIP13, one of the top-ranked co-expressing genes, was also found to interact with $\mathrm{p} 31^{\text {comet }}$ and several other mitosis regulators, although it did not make to the PPI top-ranking list mainly due to its large number of total interactors.

\section{Comparison of co-expression and PPI search results}

Nineteen genes/proteins are ranked high in both Gene Sorter co-expression and POINeT PPI lists (Tables 2 and Additional file 7: Table S7), of which 16 were in the query list (BUB1, BUB1B, CDCA8, CENP-A, CENP-E, CENP-F, ITGB3BP, KIF2C, KNTC1, MAD2L1, NDC80, NEK2, $P L K 1, S P C 25, T T K$ and $Z W I N T)$. The 3 non-query genes CCNA2, CCNB1 and CDC2 encode cyclin A2, cyclin B1 and CDC2 kinase. Similarly, comparison of co-expressing genes in Table S6 and PPI list in Table S7 found 21 common genes, with 18 in the query list $(B U B 1, B U B 1 B$, CDCA8, CENP-A, CENP-E, CENP-F, KIF2C, KNTC1, MAD2L1, NDC80, NEK2, NUF2, PLK1, SGOL2, SPC25, TTK, ZWILCH and ZWINT) and 3 non-query genes: $C C N A 2, C C N B 1$ and BRCA2. The convergence of results to well-known mitosis regulators is encouraging, reflecting that the searches have generated functionally relevant results. How much overlap one should expect from parallel co-expression and PPI analyses is hard to predict as the two analyses are based on information at mRNA and protein levels, respectively; and the PPI coverage of the proteome is usually much lower compared to transcriptional profiling for the genome.

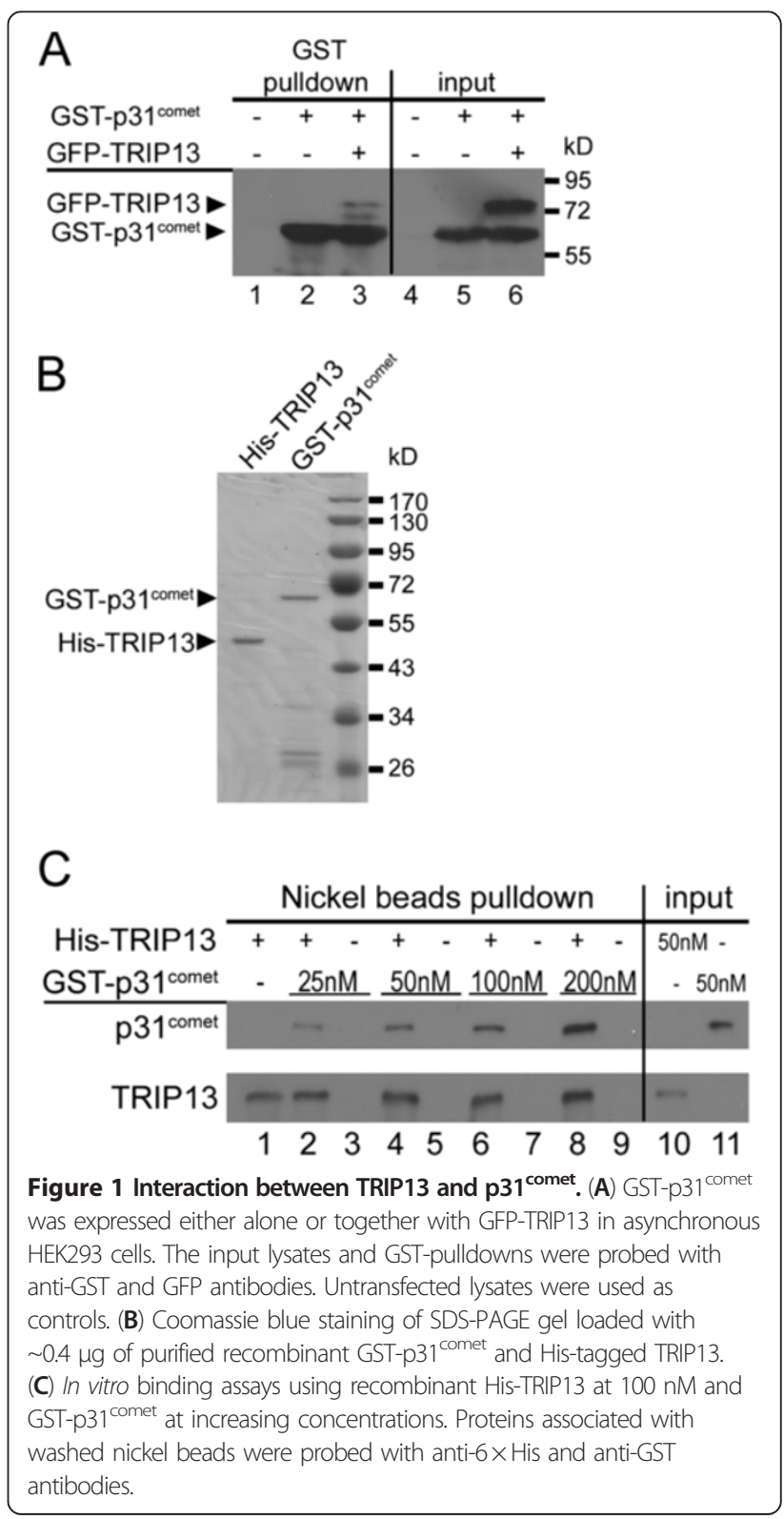


It is acknowledged that high-throughput data contains intrinsic noises that affect both co-expression and PPI analyses [60-62]. In addition, many genes/proteins may participate in multiple biological processes. Using a group of functionally associated or subcellularly co-localized genes/proteins as queries has the potential to reduce database noises and selectively screen for candidates that are functional in a specific biological process or structure. Although we are mostly interested in using such "group query" strategy in combination with online resources to identify candidate mitosis regulators for experimental validation, refining the search strategy in collaboration with computer scientists and statisticians may prove useful to apply "partial knowledge" to obtain a more comprehensive understanding of a biological process or structure.

\section{TRIP13 is a novel kinetochore protein}

To further validate the results from bioinformatics studies, subcellular localization was determined for seven candidate genes as preliminary evaluation of their potential mitotic functions. The cDNAs were cloned as GFPfusions and were all confirmed to express at expected sizes (Additional file 8: Figure. S1).

As mentioned above, TRIP13 is a top-ranking gene that co-expresses with centromere/kinetochore components, but has not been associated with any mitotic functions. The yeast, worm and mouse homologs of TRIP13 have all been implicated in meiosis recombination [63-65]. However, TRIP13 is widely expressed in somatic tissues (information from Gene Sorter). Moreover, proteomic studies have found TRIP13 interacts with p31 ${ }^{\text {comet }}$, an important spindle assembly checkpoint silencing protein [66]. The interaction is conserved in both human and mouse cells $[67,68]$. TRIP13 encodes an AAA-ATPase, is overexpressed in many cancers and is hence listed in multiple cancer signatures [31,69-71].

We first confirmed by GST-pulldown that GFPTRIP13 associates with GST-p31 ${ }^{\text {comet }}$ in cell lysates (Figure 1A). Furthermore, purified recombinant GSTp31 ${ }^{\text {comet }}$ and His-TRIP13 directly interact in vitro under physiologically relevant concentrations (our estimates of endogenous concentrations of $\mathrm{p} 31^{\text {comet }}$ and TRIP13 are both around $100 \mathrm{nM}$ ) (Figure $1 \mathrm{~B} \& \mathrm{C}$ ). In interphase cells GFP-TRIP13 is distributed in endoplasmic reticulum-like structures and partially localize at the nuclear envelope (data not shown). GFP-TRIP13 was observed to concentrate at kinetochores shortly after nuclear envelope breakdown, as evidenced by co-localization with BUBR1 and the centromere marker ACA (Figure 2A). In later prometaphase cells, GFP-TRIP13 was only
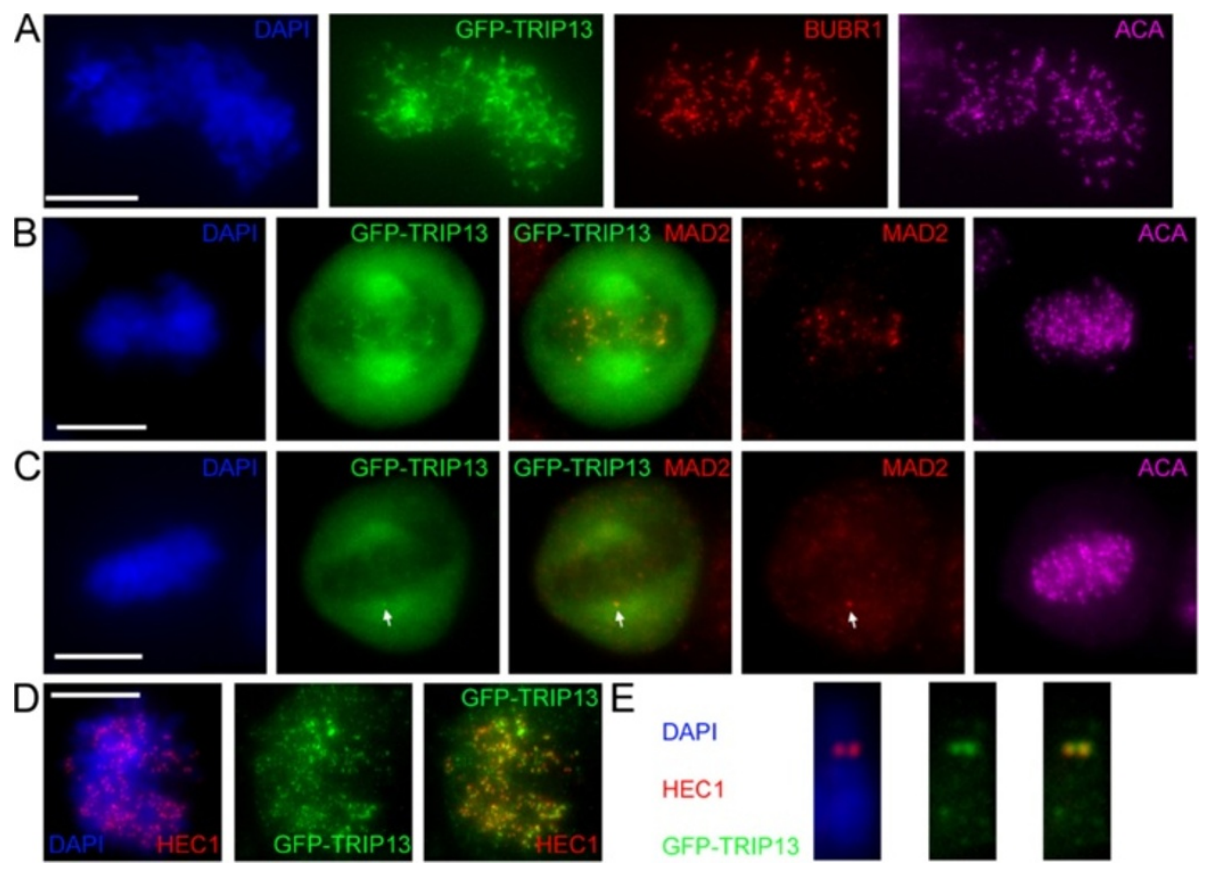

Figure 2 Characterization of novel kinetochore protein TRIP13. (A) A GFP-TRIP13 transfected HeLa cell in early prometaphase was stained for centromeres (ACA, purple), BUBR1 (red) and DNA (DAPI, blue) to compare with the GFP signals (green). Images shown are maximum projection of a z-series at $1 \mu \mathrm{m}$ interval. Bar $=10 \mu \mathrm{m}$.(B\&C) A GFP-TRIP13 transfected prometaphase cell $(\mathbf{B})$ and a cell progressing into metaphase $(\mathbf{C})$ were co-stained with anti-MAD2 antibody and ACA to show GFP-TRIP13 localization only at MAD2 positive kinetochores, such as the one indicated by arrows in (C).(D) A GFP-TRIP13 transfected cell spun onto a coverslip for mitotic chromosome spread preparation was probed with DAPI and anti-HEC1 antibody. (E) A single mitotic chromosome stained with DAPI, anti-GFP and anti-HEC1 antibodies to show kinetochore localization of GFP-TRIP13. 
observed at kinetochores that were also stained positive for SAC protein MAD2 (Figure $2 \mathrm{~B} \& \mathrm{C}$ ). Also similarly as MAD2, GFP-TRIP13 disappears from kinetochores in metaphase and anaphase cells (data not shown). The kinetochore localization of GFP-TRIP13 seems independent of microtubules, as it remains co-localized with HEC1/hNdc80 in chromosome spread preparations made from nocodazole and hypotonic buffer treated cells (Figure 2D\&E). We concluded that TRIP13 is a novel kinetochore protein that interacts with $\mathrm{p} 31^{\text {comet }}$. As SAC silencing requires energy input that utilizes hydrolysis of the $\beta-\gamma$ phosphoanhydride bond in ATP [72,73], we are testing whether TRIP13 as an AAA-ATPase facilitates $\mathrm{p} 31^{\text {comet }}$ mediated checkpoint silencing.

\section{KIAA1377 is a novel centrosomal protein}

KIAA1377 was retrieved as a top-ranking non-query protein that associates with centromere/kinetochore proteins in the PPI analyses. KIAA1377 was previously shown to localize at the midbody [52]. GFP-KIAA1377 was confirmed to localize at midbody during cytokinesis, co-localizing with microtubule bundles adjacent to two Plk1-containing discs (Figure 3A\&B). In cells showing relatively higher expression, GFP-KIAA1377 was also observed to extensively overlap with microtubule network in interphase cells and the spindle in mitotic cells (Figure 3C\&D). Most interestingly, GFP-KIAA1377 colocalizes with centrin 2 at centrosomes throughout the cell cycle except on newly assembled daughter centrioles where GFP signals are absent (Figure 3D, S/G2). In early G1 cells, the signals of GFP-KIAA1377 at centrosomes are dim when compared to those at the midbody; nonetheless they are reproducibly detectable (Figure 3D, Early G1; Additional file 9: Figure S2, Early G1). Co-staining with $\gamma$-tubulin antibody confirmed the centrosome localization pattern of GFP-KIAA1377 (Additional file 9: Figure S2). The results indicate that KIAA1377 is likely a novel centrosomal protein. As mentioned above, KIAA1377 was reported in proteomics studies to also interact with $\mathrm{p} 31^{\text {comet }}$. Studies are ongoing to further clarify potential mitotic functions of KIAA1377.

\section{Experimental characterization of other potential mitosis regulators}

Five other co-transcription hits were also cloned as GFPfusions and examined for their subcellular localization.
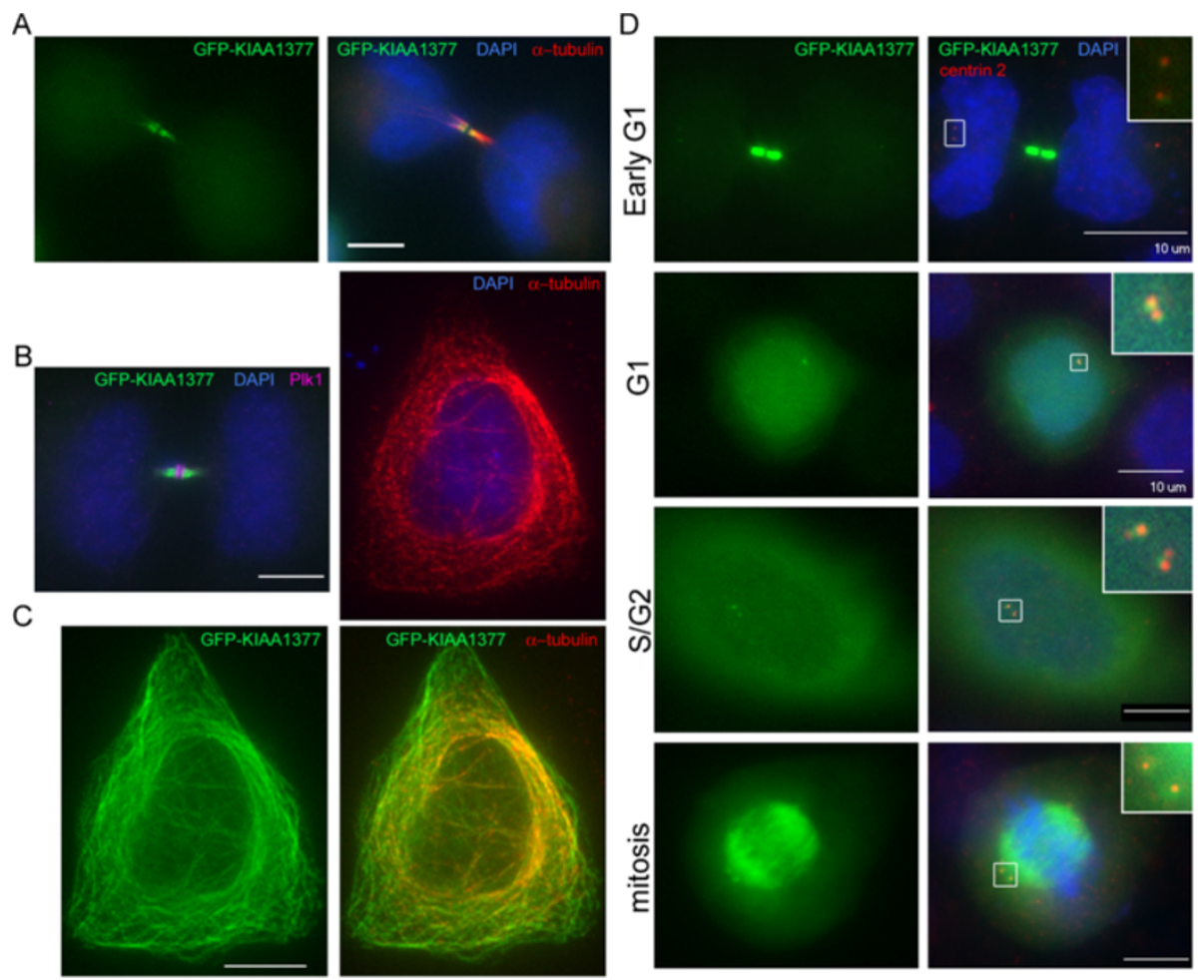

Figure 3 Subcellular localization of GFP-KIAA1377. HeLa cells transfected with GFP-KIAA1377 (green) were fixed and probed with immunofluorescence. Images at single focal planes are shown. Bar $=10 \mu \mathrm{m}$. (A\&B) Transfected cells finishing cytokinesis were co-stained with anti-a-tubulin (red in A) or anti-Plk1 antibody (purple in B) and counter-stained with DAPI for DNA (blue). (C) A transfected cell expressing higher level of GFP-KIAA1377 (green) was co-stained for a-tubulin (red) and DNA (blue) to indicate co-localization of GFP-KIAA1377 with microtubule structures. (D) GFP-KIAA1377 is localized at centrosomes. Cells at different stages of cell cycle are distinguished based on anti-centrin 2 (red) and DAPI (blue) staining. The GFP signals in different cells were adjusted to the same scale. Enlarged insets show details of boxed areas. 
Three were retrieved from both Gene Sorter and CoExSearch searches (Additonal file 6: Table S6), including $P B K$ and $M E L K$ encoding protein kinases and CDKN3 encoding dual specificity phosphatase KAP that is closely related to CDC14 phosphatases [74]. DDX39, ranked as the $61^{\text {st }}$ in the Gene Sorter search (Table 2) and encoding a RNA helicase, and C4orf46, a gene of unknown function and ranked as $32^{\text {nd }}$ in the CoExSearch result (Additional file 5; Table S5), were also included for analyses.

PBK/TOPK was previously shown to regulate cytokinesis [75]. KAP, originally discovered as a CDK inhibitor, interacts with CDK2 and CDC2 [76,77]. However, the subcellular localization of GFP-PBK and GFP-CDKN3 cannot be distinguished from that of GFP alone (Additional file 10: Figure S3). GFP is diffusely distributed in interphase cells with slightly higher accumulation in the nuclei. GFP alone was also observed to be concentrated at the midbody and, to a lesser extent, mitotic spindle (Additional file 10: Figure S3, first row). Lack of specific subcellular localization apparently does not preclude certain proteins from playing active roles during mitosis. A C-terminal tagged C4orf46-GFP shows similar localization in mitotic cells as GFP, GFP-PBK and GFPCDKN3, although in interphase cells it is primarily localized in ER like structure and nuclear envelope (Additional file 10: Figure S3, bottom row).

GFP-DDX39 and GFP-MELK displayed more interesting subcellular localization. Although the bulk of GFPDDX39 is diffuse in both the cytoplasm and nuclei, a fraction of the GFP signals co-localizes with $\gamma$-tubulin throughout the cell cycle (Figure 4). Therefore, DDX39 is also a putative centrosomal protein and its possible functions at centrosomes or during mitosis warrant further investigation. It should be noted that RNA and RNA binding proteins have been found in centrosomes [78,79]. MELK was proposed to regulate G2/M transition by phosphorylating CDC25B [80]. More recently, Xenopus MELK was found to exhibit mitosis specific localization at the cell cortex and target to the presumptive site of cleavage furrow before any signs of ingression, suggesting a role in cytokinesis regulation [81]. Using nuclear localization of CENP-F as a G2 marker [82], we found that GFP-MELK is largely cytoplasmic in G1 cells, but partially translocated into nuclei in G2 cells (Figure 5A, top row). However, in late G2/early prophase cells where discrete CENP-F foci can be discerned, the nuclear level of GFP-MELK is reduced again (Figure 5A, bottom row). Similarly to what has been reported in the Xenopus system, GFP-MELK starts to accumulate at cell cortex upon mitosis entry and becomes more evident following metaphase-to-anaphase transition (Figure 5B, 1-4). Intriguingly, one or two transient GFP-MELK bands were observed in the midzone of late anaphase cells (Figure 5B, 5-6; Figure 5C), likely marking the presumptive cleavage site as in Xenopus cells.

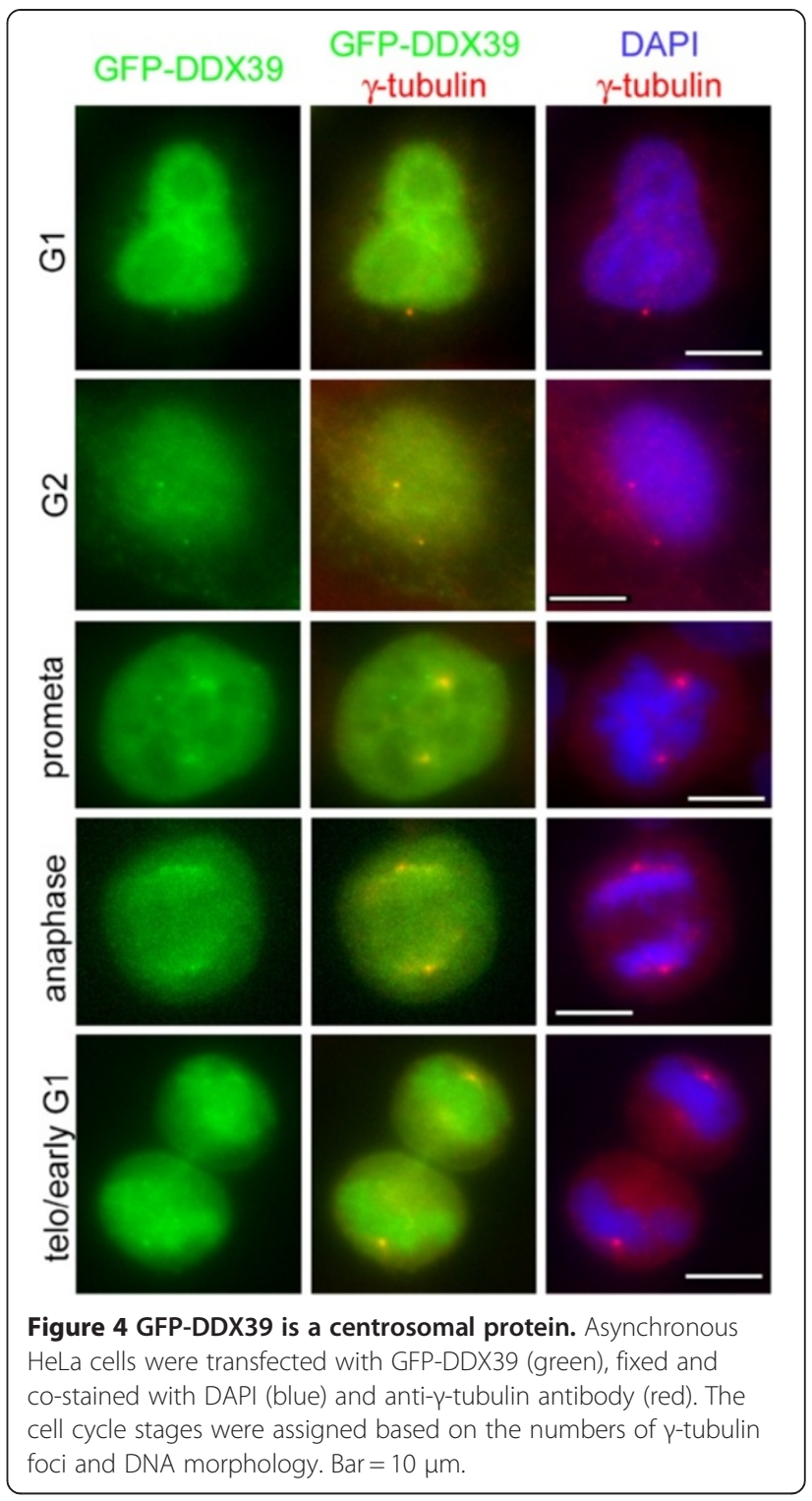

The bands coalesces as cytokinesis progresses but cortical association of GFP-MELK remains until sometime in early G1 (Figure 5B, 7-8). The dynamic localization pattern of GFP-MELK seems consistent with its proposed roles in G2/M transition and cytokinesis regulation. The apparent evolutionary conservation between Xenopus and human MELKs prompts further studies on their functioning mechanisms in regulating mitosis progression.

\section{Conclusions}

In conclusion, we have compiled so far the most comprehensive list of centromere/kinetochore proteins in human cells. Data mining of gene expression and PPI databases using the centromere/kinetochore proteins as queries have retrieved candidate novel mitosis regulators. 


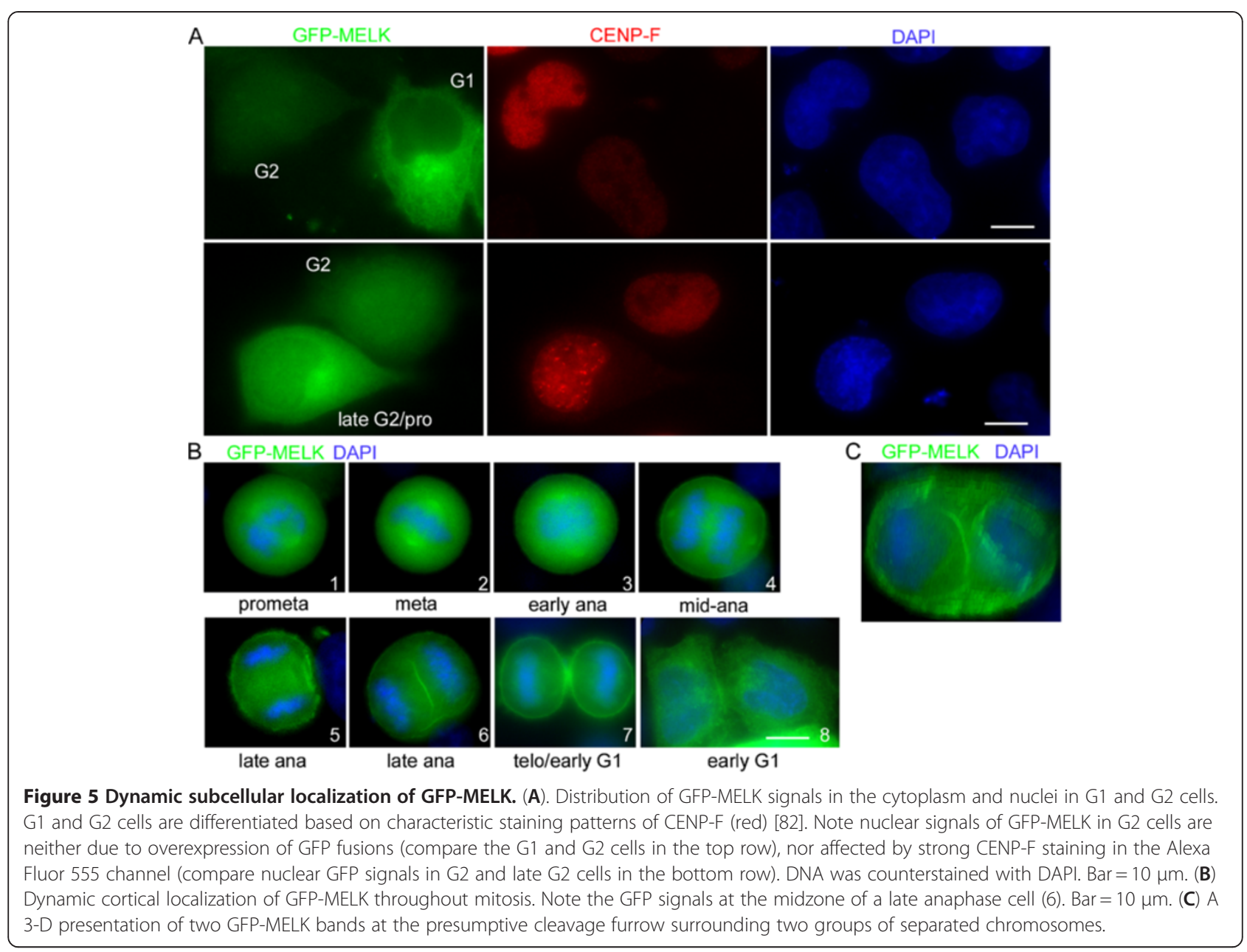

Experimental validation has discovered two novel centrosomal proteins KIAA1377 and DDX39, and one novel kinetochore protein TRIP13. Functional characterization of these proteins will likely reveal novel mechanisms of mitosis regulation. We conclude that transcriptional coexpression and PPI network analyses with known human centromere/kinetochore proteins as a query group help identify novel mitosis regulators.

\section{Methods}

\section{Literature search and gene ontology analysis}

The list of human centromere/kinetochore proteins were first derived from a previous review [16], and then updated through exhaustive abstract search in PubMed. Tracking the references during full-text literature review and screening through Gene Ontology (GO) website (http://www.geneontology.org/) also contributed to the compilation. The last amendment of the list was made on April 30, 2012. For GO analysis, the human genes annotated with "centromere" or "kinetochore" in the GO terms or IDs were filtered with "H. Sapiens" species filter and downloaded in the "gene association format" into
Microsoft Excel. The conversion between gene symbols and IDs was carried out using Gene symbol Gene ID converter [83] (http://idconverter.bioinfo.cnio.es/). The GO enrichment analysis was performed using FuncAssociate 2.0 (http://llama.med.harvard.edu/funcassociate/).

\section{Transcriptional co-expression analysis}

The transcriptional expression profiling data in the UCSC Human Gene Sorter (Mar. 2006 datasets) were used for transcriptional co-expression analysis [84]. The depository contains data of the human transcriptome in over 70 tissues and cell lines obtained on three microarray chips. Gene Sorter search returns each query with a list of genes ranked by similarity in expression patterns $[85,86]$. For each centromere/kinetochore query, the top 50 co-expressing genes on all chips were collected. A total of 155 "top 50" lists for the 64 core centromere/kinetochore components were then pooled. The Pivot Table function in Excel was used to count the occurrences of each gene in the combined list after removing queries. 
The co-expression was also analyzed later using the CoExSearch program (http://coxpresdb.jp/top_search. shtml\#CoExSearch) $[48,49]$ which accepts a group of queries to search for common co-expressing genes and rank them based on a co-expression measure "mutual rank" (MR) [49]. A total of 4401 microarray expression datasets (no overlap with data in Gene Sorter) was used for human gene co-expression analysis.

\section{Protein-protein interaction network analysis}

PPI network analysis was performed using online tools provided at the POINeT website (http://poinet.bioinformatics.tw) [52,53,87], using the 64 "core" centromere/ kinetochore proteins as a query group. Only experimentally determined interactions were used to analyze the interactions. The POINeT website has imported data from several most popular PPI databases, and ranked the proteins based on a "subnetwork specificity score" (S3 score) reflecting their enrichment in a specific biological process defined by the query group. The scoring system consists of two parts. The first part examines the ratio of the subnetwork degree to the global degree of any given node. In other words, it compares the number of PPIs (degree) between a protein (node) and members of the query group to the total number of PPIs involving the protein. The second part compares the number of PPIs involving a certain protein with members of the query group to the number of PPIs between the same protein and 1,000 randomly generated groups of the same size as the query group [52,53].

\section{Recombinant DNA, recombinant protein and In vitro protein binding assay}

DNA cloning was performed using the Gateway system (Invitrogen) [88,89]. Full-length cDNAs encoding selected proteins were amplified and cloned into pENTR-TOPO vector. The constructs were verified for DNA sequences and then recombined into different destination vectors for protein expression in E. coli or mammalian cells. Recombinant GST-p31 ${ }^{\text {comet }}$ and $6 \times$ His-TRIP13 were expressed and purified as described before $[88,89]$. In vitro binding assay with recombinant proteins was performed essentially as in [89] except that Probond nickel beads (Invitrogen) was used for pull-down.

\section{DNA transfection and immunofluorescence}

DNA transfection and immunofluorescence was performed essentially according to [90]. HeLa-M or HEK293 cells were transfected using Fugene 6 (Roche) or TransIT -LT1 (Mirus) following the manufacturers' instructions. Cells were usually fixed 24 48 hrs after transfection in $3.5 \%$ paraformaldehyde for $7 \mathrm{~min}$, extracted with KBT (10 mM Tris- $\mathrm{HCl}, \mathrm{pH} 7.5,150 \mathrm{mM} \mathrm{NaCl}, 1 \mathrm{mg} / \mathrm{ml}$ BSA and $0.2 \%$ Triton $\mathrm{X}-100)$ for $5 \mathrm{~min}$, and then blocked with KB (KBT omitting Triton X-100) for at least 5 min prior to immunofluorescence. In cases that $\gamma$-tubulin was probed, the cells were fixed and extracted simultaneously in $3.5 \%$ paraformaldehyde containing $1 \%$ Triton X-100 for $7 \mathrm{~min}$, and then blocked with KB. The list of antibodies used can be provided upon request. The images were collected by a cooled CCD camera (CoolSNAP HQ2; Photometrics) equipped on an automated Olympus IX-81 microscope using a PlanApo 60× NA 1.42 oil objective with z-step mostly set at $1 \mu \mathrm{m}$. Image acquisition and analysis were performed using Slidebook software (Intelligent Imaging Innovations) and further processed in Adobe Photoshop for presentations.

\section{Preparation of mitotic chromosome spreads}

Transfected HeLa-M cells were harvested after $16 \mathrm{hr}$ treatment with nocodazole $(60 \mathrm{ng} / \mathrm{ml}$ final concentration) and swollen for $30 \mathrm{~min}$ in $75 \mathrm{mM} \mathrm{KCl}$ at room temperature. One millilitre of cell suspension was added to a $35 \mathrm{~mm}$ dish containing coverslips, and spun at $1,000 \times \mathrm{g}$ for $12 \mathrm{~min}$ in a Legend RT-Plus centrifuge (Thermo Scientific) on top of a $15 \mathrm{ml}$ tube holder fitted inside a hanging bucket. The chromosome spreads were then fixed and processed for immunofluorescence.

\section{Additional files}

Additional file 1: Table S1. Compilation of human centromerekinetochore proteins.

Additional file 2: Table S2. Comparison of the centromere/ kinetochore list compiled in this work with GO annotated centromere/kinetochore genes.

Additional file 3: Table S3. Summary table of all "top 50" genes that co-express with the 64 core centromere/kinetochore queries in Gene Sorter search.

Additional file 4: Table S4. GO enrichment analysis of genes listed in Table 2.

Additional file 5: Table S5. Top-ranking co-expressing genes retrieved by CoExSearch program.

Additional file 6: Table S6. Genes co-expressing with the 64 core centromere/kinetochore components in both Gene Sorter and CoExSearch searches. Highlighed genes were experimentally tested in this work.

Additional file 7: Table S7. Top-ranking genes whose encoded proteins interact with the core centromere/kinetochore components.

Additional file 8: Figure S1. Western blot of GFP-fusion proteins experimentally tested in this work. Except that C40rf46 was fused with a C-terminal GFP tag, all other constructs contain N-terminal GFP. Asynchronous HEK293 (for TRIP13 and KIAA) and HeLa cells (for the rest) were transfected and cell lysates were harvested $24 \sim 48$ hrs later for anti-GFP Western blot.

Additional file 9: Figure S2. Co-localization of GFP-KIAA1377 with $\gamma$-tubulin throughout the cell cycle. HeLa cells transfected with GFP-KIAA1377 were fixed and stained with DAPI (blue) and anti- $\gamma$-tubulin antibody (red). In the bottom row, note no bleedthrough of strong $\gamma$-tubulin signals to the green channel in the untransfected cell on the left. Bar $=10 \mu \mathrm{m}$.

Additional file 10: Figure S3. Comparison of subcellular localization of GFP, GFP-CDKN3, GFP-PBK and C4orf46-GFP. Cells undergoing cytokinesis or in interphase or mitosis were probed. DNA is 
counterstained with DAPI (blue) and microtubules are stained with anti-a-tubulin antibody (red). Note microtubule staining is not always easily discernible because single focal plane images were shown, and the contrast is optimized to show the microtubule bundles at the midbody in cells undergoing cytokinesis. Bar $=10 \mu \mathrm{m}$.

\section{Abbreviations}

PPI: Protein-protein interaction; SAC: Spindle assembly checkpoint; APC/C: Anaphase promoting complex/cyclosome; GO: Gene ontology; ACA: Anti-centromere autoimmune.

\section{Competing interests}

The authors declared that they have no competing interests.

\section{Acknowledgements}

We thank Drs. Jianhua Ruan (University of Texas at San Antonio), Justin Ways, Andrea Kalinoski and David Allison (all from University of Toledo, College of Medicine) for discussions. STL was funded by deArce Memorial Fund and NSF grant MCB-1052413.

\section{Author details}

${ }^{1}$ Department of Biological Sciences, University of Toledo, Toledo, $\mathrm{OH} 43606$, USA. ${ }^{2}$ Ruijin Hospital, Shanghai 200025, China.

\section{Authors' contributions}

STL conceived the study and performed imaging experiments. AT and STL performed literature search and analyzed retrieved results. AT, PO, SS, ZG and STL performed gene cloning and mammalian expression experiments. KW carried out recombinant protein expression and pulldown experiments. STL wrote the manuscript. All authors read and approved the final manuscript.

Received: 13 February 2012 Accepted: 19 June 2012

Published: 19 June 2012

\section{References}

1. Pines J, Rieder $C L$ : Re-staging mitosis: a contemporary view of mitotic progression. Nature cell biology 2001, 3(1):E3-E6.

2. Muller GA, Engeland $K$ : The central role of $\mathrm{CDE} / \mathrm{CHR}$ promoter elements in the regulation of cell cycle-dependent gene transcription. FEBS $J$, 277(4):877-893.

3. Laoukili J, Kooistra MR, Bras A, Kauw J, Kerkhoven RM, Morrison A, Clevers H, Medema $\mathrm{RH}$ : FoxM1 is required for execution of the mitotic programme and chromosome stability. Nature cell biology 2005, 7(2):126-136.

4. Furuno N, den Elzen N, Pines J: Human cyclin A is required for mitosis until mid prophase. The Journal of cell biology 1999, 147(2):295-306.

5. Musacchio A, Salmon ED: The spindle-assembly checkpoint in space and time. Nat Rev Mol Cell Biol 2007, 8(5):379-393.

6. Potapova TA, Daum JR, Pittman BD, Hudson JR, Jones TN, Satinover DL, Stukenberg PT, Gorbsky GJ: The reversibility of mitotic exit in vertebrate cells. Nature 2006, 440(7086):954-958.

7. Cheeseman IM, Desai A: Molecular architecture of the kinetochoremicrotubule interface. Nature reviews 2008, 9(1):33-46.

8. Chan GK, Liu ST, Yen TJ: Kinetochore structure and function. Trends Cell Biol 2005, 15(11):589-598.

9. Santaguida S, Musacchio A: The life and miracles of kinetochores. EMBO J 2009, 28(17):2511-2531.

10. Perpelescu M, Fukagawa T: The ABCs of CENPs. Chromosoma 2011, 120(5):425-446.

11. Amor DJ, Kalitsis $P$, Sumer $H$, Choo KH: Building the centromere: from foundation proteins to 3D organization. Trends Cell Biol 2004, 14(7):359-368

12. Ohta S, Bukowski-Wills JC, Sanchez-Pulido L, Alves Fde L, Wood L, Chen ZA, Platani M, Fischer L, Hudson DF, Ponting CP, et al: The protein composition of mitotic chromosomes determined using multiclassifier combinatorial proteomics. Cell 2010, 142(5):810-821.

13. Cusick ME, Klitgord N, Vidal M, Hill DE: Interactome: gateway into systems biology. Hum Mol Genet 2005, 14(Spec No. 2):R171-R181.

14. Rhodes DR, Chinnaiyan AM: Integrative analysis of the cancer transcriptome. Nat Genet 2005, 37(Suppl):S31-S37.
15. Eisen MB, Spellman PT, Brown PO, Botstein D: Cluster analysis and display of genome-wide expression patterns. Proc Natl Acad Sci U S A 1998, 95(25):14863-14868.

16. Jablonski SA, Liu ST, Yen TJ: Targeting the kinetochore for mitosis-specific inhibitors. Cancer Biol Ther 2003, 2(3):236-241.

17. Meraldi $P$, McAinsh AD, Rheinbay E, Sorger PK: Phylogenetic and structural analysis of centromeric DNA and kinetochore proteins. Genome Biol 2006, 7(3):R23.

18. Gorbsky GJ, Ricketts WA: Differential expression of a phosphoepitope at the kinetochores of moving chromosomes. The Journal of cell biology 1993, 122(6):1311-1321.

19. Ahonen LJ, Kallio MJ, Daum JR, Bolton M, Manke IA, Yaffe MB, Stukenberg PT, Gorbsky GJ: Polo-like kinase 1 creates the tension-sensing 3 F3/2 phosphoepitope and modulates the association of spindle-checkpoint proteins at kinetochores. Curr Biol 2005, 15(12):1078-1089.

20. Wong OK, Fang G: Plx1 is the 3 F3/2 kinase responsible for targeting spindle checkpoint proteins to kinetochores. The Journal of cell biology 2005, 170(5):709-719.

21. Wong OK, Fang G: Cdk1 phosphorylation of BubR1 controls spindle checkpoint arrest and Plk1-mediated formation of the 3 F3/2 epitope. The Journal of cell biology 2007, 179(4):611-617.

22. Peters JM, Tedeschi A, Schmitz J: The cohesin complex and its roles in chromosome biology. Genes Dev 2008, 22(22):3089-3114.

23. Hirano T: Condensins: organizing and segregating the genome. Curr Biol 2005, 15(7):R265-R275.

24. Mishra RK, Chakraborty P, Arnaoutov A, Fontoura BM, Dasso M: The Nup107-160 complex and gamma-TuRC regulate microtubule polymerization at kinetochores. Nature cell biology, 12(2):164-169.

25. Ashburner M, Ball CA, Blake JA, Botstein D, Butler H, Cherry JM, Davis AP, Dolinski K, Dwight SS, Eppig JT, et al: Gene ontology: tool for the unification of biology. The Gene Ontology Consortium. Nat Genet 2000, 25(1):25-29.

26. Steensgaard P, Garre M, Muradore I, Transidico P, Nigg EA, Kitagawa K, Earnshaw WC, Faretta M, Musacchio A: Sgt1 is required for human kinetochore assembly. EMBO reports 2004, 5(6):626-631.

27. Mukhopadhyay D, Arnaoutov A, Dasso M: The SUMO protease SENP6 is essential for inner kinetochore assembly. The Journal of cell biology 2010, 188(5):681-692.

28. Zhang B, Horvath S: A general framework for weighted gene co-expression network analysis. Stat Appl Genet Mol Biol 2005, 4:Article17.

29. Benson M, Breitling R: Network theory to understand microarray studies of complex diseases. Curr Mol Med 2006, 6(6):695-701.

30. Lee HK, Hsu AK, Sajdak J, Qin J, Pavlidis P: Coexpression analysis of human genes across many microarray data sets. Genome Res 2004, 14(6):1085-1094.

31. Rhodes DR, Yu J, Shanker K, Deshpande N, Varambally R, Ghosh D, Barrette T, Pandey A, Chinnaiyan AM: Large-scale meta-analysis of cancer microarray data identifies common transcriptional profiles of neoplastic transformation and progression. Proc Natl Acad Sci U S A 2004, 101(25):9309-9314.

32. Stuart JM, Segal E, Koller D, Kim SK: A gene-coexpression network for global discovery of conserved genetic modules. Science (New York, NY 2003, 302(5643):249-255.

33. Zhang W, Morris QD, Chang R, Shai O, Bakowski MA, Mitsakakis N, Mohammad N, Robinson MD, Zirngibl R, Somogyi E, et al: The functional landscape of mouse gene expression. J Biol 2004, 3(5):21.

34. Ruan J, Dean AK, Zhang W: A general co-expression network-based approach to gene expression analysis: comparison and applications. BMC Syst Biol, 4:8.

35. Mefford D, Mefford JA: Enumerating the gene sets in breast cancer, a "direct" alternative to hierarchical clustering. BMC Genomics, 11(1):482.

36. Starr DA, Saffery R, Li Z, Simpson AE, Choo KH, Yen TJ, Goldberg ML: HZwint-1, a novel human kinetochore component that interacts with HZW10. Journal of cell science 2000, 113(Pt 11):1939-1950.

37. Uhlmann F: A matter of choice: the establishment of sister chromatid cohesion. EMBO reports 2009, 10(10):1095-1102.

38. Kumar A, Girimaji SC, Duvvari MR, Blanton SH: Mutations in STIL, encoding a pericentriolar and centrosomal protein, cause primary microcephaly. Am J Hum Genet 2009, 84(2):286-290. 
39. Maxwell CA, Keats JJ, Crainie M, Sun X, Yen T, Shibuya E, Hendzel M, Chan G, Pilarski LM: RHAMM is a centrosomal protein that interacts with dynein and maintains spindle pole stability. Molecular biology of the cell 2003, 14(6):2262-2276.

40. Lagana A, Dorn JF, De Rop V, Ladouceur AM, Maddox AS, Maddox PS: A small GTPase molecular switch regulates epigenetic centromere maintenance by stabilizing newly incorporated CENP-A. Nature cell biology 2010, 12(12):1186-1193.

41. Okada M, Okawa K, Isobe T, Fukagawa T: CENP-H-containing complex facilitates centromere deposition of CENP-A in cooperation with FACT and CHD1. Molecular biology of the cell 2009, 20(18):3986-3995.

42. Raemaekers T, Ribbeck K, Beaudouin J, Annaert W, Van Camp M, Stockmans I, Smets N, Bouillon R, Ellenberg J, Carmeliet G: NuSAP, a novel microtubule-associated protein involved in mitotic spindle organization. The Journal of cell biology 2003, 162(6):1017-1029.

43. Seki A, Fang G: CKAP2 is a spindle-associated protein degraded by APC/ C-Cdh1 during mitotic exit. J Biol Chem 2007, 282(20):15103-15113.

44. Foltz DR, Jansen LE, Bailey AO, Yates JR 3rd, Bassett EA, Wood S, Black BE, Cleveland DW: Centromere-specific assembly of CENP-a nucleosomes is mediated by HJURP. Cell 2009, 137(3):472-484.

45. Foltz DR, Jansen LE, Black BE, Bailey AO, Yates JR 3rd, Cleveland DW: The human CENP-A centromeric nucleosome-associated complex. Nature cell biology 2006, 8(5):458-469.

46. Nayak T, Edgerton-Morgan H, Horio T, Xiong Y, De Souza CP, Osmani SA, Oakley BR: Gamma-tubulin regulates the anaphase-promoting complex/ cyclosome during interphase. The Journal of cell biology, 190(3):317-330.

47. Prasanth SG, Prasanth KV, Stillman B: Orc6 involved in DNA replication, chromosome segregation, and cytokinesis. Science (New York, NY 2002, 297(5583):1026-1031.

48. Obayashi T, Kinoshita K: Rank of correlation coefficient as a comparable measure for biological significance of gene coexpression. DNA Res 2009, 16(5):249-260

49. Obayashi T, Hayashi S, Shibaoka M, Saeki M, Ohta H, Kinoshita K. COXPRESdb: a database of coexpressed gene networks in mammals. Nucleic Acids Res 2008, 36(Database issue):D77-D82

50. Chan KL, Palmai-Pallag T, Ying S, Hickson ID: Replication stress induces sister-chromatid bridging at fragile site loci in mitosis. Nature cell biology 2009, 11(6):753-760.

51. Dammermann A, Pemble H, Mitchell BJ, McLeod I, Yates JR 3rd, Kintner $C$, Desai $A B$, Oegema K: The hydrolethalus syndrome protein HYLS-1 links core centriole structure to cilia formation. Genes Dev 2009, 23(17):2046-2059.

52. Chen TC, Lee SA, Hong TM, Shih JY, Lai JM, Chiou HY, Yang SC, Chan CH, Kao $C Y$, Yang PC, et al: From midbody protein-protein interaction network construction to novel regulators in cytokinesis. Journal of proteome research 2009, 8(11):4943-4953.

53. Chen TC, Lee $S A$, Chan CH, Juang YL, Hong YR, Huang YH, Lai JM, Kao CY, Huang $C Y$ : Cliques in mitotic spindle network bring kinetochoreassociated complexes to form dependence pathway. Proteomics 2009, 9(16):4048-4062

54. Kitajima TS, Sakuno T, Ishiguro K, lemura S, Natsume T, Kawashima SA, Watanabe $Y$ : Shugoshin collaborates with protein phosphatase $2 A$ to protect cohesin. Nature 2006, 441(7089):46-52.

55. Foley EA, Maldonado M, Kapoor TM: Formation of stable attachments between kinetochores and microtubules depends on the B56-PP2A phosphatase. Nature cell biology 2011, 13(10):1265-1271.

56. Cayrol C, Cougoule C, Wright M: The beta2-adaptin clathrin adaptor interacts with the mitotic checkpoint kinase BubR1. Biochem Biophys Res Commun 2002, 298(5):720-730.

57. Royle SJ, Bright NA, Lagnado L: Clathrin is required for the function of the mitotic spindle. Nature 2005, 434(7037):1152-1157.

58. Lin $\mathrm{CH}, \mathrm{Hu} \mathrm{CK}$, Shih HM: Clathrin heavy chain mediates TACC3 targeting to mitotic spindles to ensure spindle stability. The Journal of cell biology 2010, 189(7):1097-1105.

59. Nakanishi A, Han X, Saito H, Taguchi K, Ohta Y, Imajoh-Ohmi S, Miki Y: Interference with BRCA2, which localizes to the centrosome during $S$ and early $\mathrm{M}$ phase, leads to abnormal nuclear division. Biochem Biophys Res Commun 2007, 355(1):34-40.

60. Deane CM, Salwinski L, Xenarios I, Eisenberg D: Protein interactions: two methods for assessment of the reliability of high throughput observations. Mol Cell Proteomics 2002, 1(5):349-356.
61. Bader JS, Chaudhuri A, Rothberg JM, Chant J: Gaining confidence in high-throughput protein interaction networks. Nat Biotechnol 2004, 22(1):78-85

62. Draghici S, Khatri P, Eklund AC, Szallasi Z: Reliability and reproducibility issues in DNA microarray measurements. Trends Genet 2006, 22(2):101-109.

63. Li XC, Schimenti JC: Mouse pachytene checkpoint 2 (trip13) is required for completing meiotic recombination but not synapsis. PLOS Genet 2007, 3(8):e130.

64. Roig I, Dowdle JA, Toth A, de Rooij DG, Jasin M, Keeney S: Mouse TRIP13/ $\mathrm{PCH} 2$ is required for recombination and normal higher-order chromosome structure during meiosis. PLOS Genet 2010, 6(8).

65. Wojtasz L, Daniel K, Roig I, Bolcun-Filas E, Xu H, Boonsanay V, Eckmann CR, Cooke HJ, Jasin M, Keeney S, et al: Mouse HORMAD1 and HORMAD2, two conserved meiotic chromosomal proteins, are depleted from synapsed chromosome axes with the help of TRIP13 AAA-ATPase. PLoS Genet 2009, 5(10):e1000702.

66. Habu T, Kim SH, Weinstein J, Matsumoto T: Identification of a MAD2-binding protein, CMT2, and its role in mitosis. EMBO J 2002, 21(23):6419-6428.

67. Rual JF, Venkatesan K, Hao T, Hirozane-Kishikawa T, Dricot A, Li N, Berriz GF, Gibbons FD, Dreze M, Ayivi-Guedehoussou N, et al: Towards a proteome-scale map of the human protein-protein interaction network. Nature 2005, 437(7062):1173-1178.

68. Stelzl U, Worm U, Lalowski M, Haenig C, Brembeck FH, Goehler H, Stroedicke M, Zenkner M, Schoenherr A, Koeppen S, et al: A human protein-protein interaction network: a resource for annotating the proteome. Cell 2005, 122(6):957-968.

69. Yasugi T, Vidal M, Sakai H, Howley PM, Benson JD: Two classes of human papillomavirus type $16 \mathrm{E} 1$ mutants suggest pleiotropic conformational constraints affecting E1 multimerization, E2 interaction, and interaction with cellular proteins. J Virol 1997, 71(8):5942-5951.

70. Carter SL, Eklund AC, Kohane IS, Harris LN, Szallasi Z: A signature of chromosomal instability inferred from gene expression profiles predicts clinical outcome in multiple human cancers. Nat Genet 2006, 38(9):1043-1048.

71. Martin KJ, Patrick DR, Bissell MJ, Fournier MV: Prognostic breast cancer signature identified from 3D culture model accurately predicts clinical outcome across independent datasets. PLoS One 2008, 3(8):e2994.

72. Miniowitz-Shemtov S, Teichner A, Sitry-Shevah D, Hershko A: ATP is required for the release of the anaphase-promoting complex/cyclosome from inhibition by the mitotic checkpoint. Proc Natl Acad Sci U S A 2010, 107(12):5351-5356.

73. Teichner A, Eytan E, Sitry-Shevah D, Miniowitz-Shemtov S, Dumin E, Gromis J, Hershko A: p31comet promotes disassembly of the mitotic checkpoint complex in an ATP-dependent process. Proc Natl Acad Sci U S A 2011, 108(8):3187-3192.

74. Patterson Kl, Brummer T, O'Brien PM, Daly RJ: Dual-specificity phosphatases: critical regulators with diverse cellular targets. Biochem J 2009, 418(3):475-489.

75. Abe Y, Takeuchi T, Kagawa-Miki L, Ueda N, Shigemoto K, Yasukawa M, Kito K: A mitotic kinase TOPK enhances Cdk1/cyclin B1-dependent phosphorylation of PRC1 and promotes cytokinesis. J Mol Biol 2007, 370(2):231-245.

76. Hannon GJ, Casso D, Beach D: KAP: a dual specificity phosphatase that interacts with cyclin-dependent kinases. Proc Natl Acad Sci U S A 1994, 91(5):1731-1735.

77. Poon RY, Hunter T: Dephosphorylation of Cdk2 Thr160 by the cyclin-dependent kinase-interacting phosphatase KAP in the absence of cyclin. Science (New York, NY 1995, 270(5233):90-93.

78. Song MH, Aravind L, Muller-Reichert T, O'Connell KF: The conserved protein SZY-20 opposes the Plk4-related kinase ZYG-1 to limit centrosome size. Developmental cell 2008, 15(6):901-912.

79. Alliegro MC, Alliegro MA: Centrosomal RNA correlates with intron-poor nuclear genes in Spisula oocytes. Proc Natl Acad Sci U S A 2008, 105(19):6993-6997.

80. Davezac N, Baldin V, Blot J, Ducommun B, Tassan JP: Human pEg3 kinase associates with and phosphorylates CDC25B phosphatase: $a$ potential role for pEg3 in cell cycle regulation. Oncogene 2002 , 21(50):7630-7641.

81. Le Page Y, Chartrain I, Badouel C, Tassan JP: A functional analysis of MELK in cell division reveals a transition in the mode of cytokinesis 
during Xenopus development. Journal of cell science 2011, 124(Pt 6):958-968.

82. Liao H, Winkfein RJ, Mack G, Rattner JB, Yen TJ: CENP-F is a protein of the nuclear matrix that assembles onto kinetochores at late $\mathrm{G} 2$ and is rapidly degraded after mitosis. J Cell Biol 1995, 130:507-518.

83. Alibes A, Yankilevich P, Canada A, Diaz-Uriarte R: IDconverter and IDClight: conversion and annotation of gene and protein IDs. BMC Bioinforma 2007, 8:9.

84. Kent WJ, Hsu F, Karolchik D, Kuhn RM, Clawson H, Trumbower H, Haussler D: Exploring relationships and mining data with the UCSC Gene Sorter. Genome Res 2005, 15(5):737-741.

85. Su Al, Cooke MP, Ching KA, Hakak Y, Walker JR, Wiltshire T, Orth AP, Vega RG, Sapinoso LM, Mogrich A, et al: Large-scale analysis of the human and mouse transcriptomes. Proc Natl Acad Sci U S A 2002, 99(7):4465-4470.

86. Su Al, Wiltshire T, Batalov S, Lapp H, Ching KA, Block D, Zhang J, Soden R, Hayakawa M, Kreiman G, et al: A gene atlas of the mouse and human protein-encoding transcriptomes. Proc Natl Acad Sci U S A 2004, 101(16):6062-6067.

87. Lee $\mathrm{SA}$, Chan $\mathrm{CH}$, Chen TC, Yang CY, Huang KC, Tsai CH, Lai JM, Wang FS, Kao CY, Huang CY: POINeT: protein interactome with sub-network analysis and hub prioritization. BMC Bioinforma 2009, 10:114.

88. Tipton AR, Tipton M, Yen T, Liu ST: Closed MAD2 (C-MAD2) is selectively incorporated into the mitotic checkpoint complex (MCC). Cell cycle (Georgetown, Tex 2011, 10(21):3740-3750.

89. Tipton AR, Wang K, Link L, Bellizzi JJ, Huang H, Yen T, Liu ST: BUBR1 and Closed MAD2 (C-MAD2) Interact Directly to Assemble a Functional Mitotic Checkpoint Complex. J Biol Chem 2011, 286(24):21173-21179.

90. Liu ST, Hittle JC, Jablonski SA, Campbell MS, Yoda K, Yen TJ: Human CENP-I specifies localization of CENP-F, MAD1 and MAD2 to kinetochores and is essential for mitosis. Nature cell biology 2003, 5(4):341-345.

doi:10.1186/1471-2121-13-15

Cite this article as: Tipton et al: Identification of novel mitosis regulators through data mining with human centromere/kinetochore proteins as group queries. BMC Cell Biology 2012 13:15.

\section{Submit your next manuscript to BioMed Central and take full advantage of:}

- Convenient online submission

- Thorough peer review

- No space constraints or color figure charges

- Immediate publication on acceptance

- Inclusion in PubMed, CAS, Scopus and Google Scholar

- Research which is freely available for redistribution 